\title{
Effect of acute cytomegalovirus infection on drug-induced SLE
}

\author{
Ami Schattner' ${ }^{1}$, Zeev Sthoeger and David Geltner
}

Departments of Medicine 1 A and C, and R. Ben-Ari Institute of Clinical Immunology, Kaplan Hospital, Rehovot 76100, affiliated to the Hebrew University and Hadassah Medical School, Jerusalem, Israel

\begin{abstract}
Summary: A 58 year old woman developed systemic symptoms, interstitial lung disease, splenomegaly, leukopenia and anti-histone and anti-nuclear antibodies (ANA), while treated with hydralazine for hypertension. Five months after presentation she was admitted with high fever, skin rash and atypical lymphocytosis due to acute cytomegalovirus (CMV) infection. Worsening leukopenia and increased ANA were found, and high titres of anti-DNA antibodies, anti-cardiolipin antibodies and rheumatoid factors appeared. Hydralazine was stopped and the patient gradually became asymptomatic. All autoantibodies spontaneously disappeared (over 16 weeks), and the white cell count and spleen size became normal. The patient was found to be a slow acetylator and to have both HLA-DR4 and selective IgA deficiency.

Thus, a multifactorial genetic susceptibility to develop drug-induced lupus was brought out in stages first by hydralazine and then by CMV, yet all manifestations and autoantibodies resolved spontaneously, demonstrating the complex interplay of varied environmental factors with a genetic predisposition in the pathogenesis of autoimmunity.
\end{abstract}

\section{Introduction}

The pathogenesis of autoimmune diseases is thought to be multifactorial with a complex interplay of genetic, hormonal and environmental factors.' Among 'exogenous' environmental events, which precipitate the appearance of autoantibodies and the development of clinically manifest autoimmune disease, infective agents, especially viruses, and certain drugs, notably hydralazine and procainamide, may have an important role. ${ }^{2,3}$ The following report illustrates the importance and interaction of both types of environmental factors in the pathogenesis of drug-induced systemic lupus erythematosus (SLE) in a genetically susceptible patient, which was entirely reversible upon removal of the drug and recovery from the acute infection.

\section{Case report}

A 58 year old woman with a 4-year history of mild essential hypertension treated with hydralazine $(100 \mathrm{mg} /$ day) was examined over 5 months for progressive fatigue, dyspnoea and palpitations on exertion, night sweats, anorexia, nausea and a

Correspondence: A. Schattner, M.D., Department of Medicine A, Kaplan Hospital, Rehovot 76100, Israel. Accepted: 7 February 1994 weight loss of $9 \mathrm{~kg}$. Splenomegaly $(3 \mathrm{~cm})$ was the only abnormality on physical examination. The white blood cell count (WBC) was $2.6 \times 10^{9} / 1$ and after 3 months $1.65 \times 10^{9} / 1$ with 775 granulocytes per microlitre and the same number of lymphocytes, a haemoglobin of $10.8 \mathrm{~g} / \mathrm{dl}$ (normocytic) and $227 \times 10^{9} / 1$ platelets. The urine and renal function as well as the liver function tests, electrocardiogram and chest $\mathrm{X}$-ray were normal. No autoantibodies were found except for a low titre of ANA $(+1$, speckled) and anti-histone antibodies (identified later in a stored frozen serum sample). Pulmonary studies showed arterial hypoxaemia and volume restriction with normal perfusion lung scintigram and computed tomographic (CT) scan, compatible with interstitial lung disease.

Five months after presentation the patient developed high fever $\left(39.4^{\circ} \mathrm{C}\right)$ with a diffuse nonpruritic maculo-papular rash and was admitted with no further physical findings. The ESR was $100 \mathrm{~mm} /$ hour. WBC count was $1.2 \times 10^{9} / 1$ and there were $120 / \mu \mathrm{l}$ atypical lymphocytes. A bone marrow aspiration and biopsy showed a hyperplastic marrow. Splenomegaly of $18 \mathrm{~cm}$ was confirmed by abdominal ultrasound and the CT scan which revealed no other pathology. In addition to a higher titre of anti-histone antibodies, autoantibodies now included ANA ( +4 , homogenous), anti-double-stranded DNA antibodies (Ab) $(+3$ by 
the crithidia lucillae indirect immunofluorescence assay and confirmed by ELISA), rheumatoid factors (latex 1/2,560) and anti-cardiolipin antibodies (a markedly high titre by ELISA of both IgG and IgM antibodies). Coombs' test was negative, as were the coagulation tests for a lupus anticoagulant, VDRL and LE cell preparations. Diffuse hypergammaglobulinaemia was seen on protein electrophoresis. Liver and renal function tests remained normal, as well as the serum complement levels. Fibrin degradation products (FDP) were $>45 \mu \mathrm{g} / \mathrm{ml}$, fibrinogen $430 \mathrm{mg} / \mathrm{dl}$, prothrombin time 6 seconds ( $50 \%$ of control), APTT 27 seconds (control 30 seconds) and the platelet count remained normal. C-reactive protein (CRP) was $48 \mathrm{mg} / \mathrm{dl}$ (normal $<6 \mathrm{mg} / \mathrm{dl}$ ).

Hydralazine treatment was stopped and broadspectrum antibiotics were administered intravenously since the patient was febrile and granulocytopenic. The fever went down and the rash cleared in 5 days. This was followed by a gradual disappearance of the anorexia, dyspnoea and fatigue over 6 weeks. All bacterial cultures were negative but viral serology was positive for cytomegalovirus (a rise of IgG Ab 1:40 to 1:160 and positive $\operatorname{IgM~Ab}$ in a maximal titre of $1: 160$ ), and negative for Epstein-Barr virus $(<1: 10)$ and a panel of other viruses.

The patient was discharged and over 4 months the spleen became impalpable. The ESR decreased to $45 \mathrm{~mm}$ /hour, haemoglobin and WBC increased to $13.7 \mathrm{~g} / \mathrm{dl}$ and $6.2 \times 10^{9} / 1$, respectively. Autoantibodies decreased in titre and over 16 weeks became undetectable except for ANA which was the last to disappear at about 6 months after hydralazine withdrawal. Serum immunoglobulins were IgG 16 then $13.5(12.4 \pm 2.2)$, IgM 3.8 then $1.49(1.2 \pm 0.35)$, and $\operatorname{IgA} 0.57 \mathrm{~g} / 1$ unchanged $(2.8 \pm 0.7)$. HLA-DR4 and a slow acetylator phenotype were found.

Two years later the patient remains asymptomatic with no medications except for nifedipine for her hypertension. She has no further evidence of lung disease neither clinically nor on repeat pulmonary function studies and arterial blood gas analysis. Her follow-up CMV titres are negative for IgM and positive for anti-CMV IgG antibodies in a titre of $1: 40$.

\section{Comment}

This patient had several predisposing factors to develop drug-induced SLE. They include female gender, slow acetylator phenotype and HLA-DR4, which was identified in over $70 \%$ of patients with hydralazine-related lupus. ${ }^{4-6}$ Partial IgA deficiency also appears to predispose to autoantibody forma- tion and autoimmune disease, often SLE. ${ }^{7}$ Its persistence over a follow-up period of 2 years suggests a congenital deficiency, though selective IgA deficiency can also be drug-induced (for example, by D-penicillamine, diphenylhydantoin) and take months to resolve after discontinuation of the drug. ${ }^{8}$ Hydralazine treatment, even at a low dose of $100 \mathrm{mg} /$ day was found to be associated with druginduced lupus in about $8 \%$ of women and cause ANA positivity in many more. ${ }^{5}$ We believe that hydralazine caused the first phase of the patient's illness, which included systemic symptoms, interstitial lung involvement, splenomegaly, leukopenia and ANA. This is supported by the demonstration of anti-histone antibodies and the characteristic sparing of the skin, kidneys and central nervous system.9 However, the marked leukopenia is unusual and may be related to the splenomegaly or to specific antibodies. ${ }^{10}$

The patient was then admitted after the sudden appearance of high fever and a rash. Further splenomegaly and leukopenia were noted, as well as a transient increase in atypical lymphocytes, CRP, fibrin degradation products, immunoglobulins and several autoantibodies. This presentation was most probably due to an acute CMV infection as confirmed by the appearance of specific IgM antibodies, the negative serologies for other viruses, the lack of other demonstrable cause and the full recovery.

The marked quantitative and qualitative change in autoantibody pattern seen following the acute viral infection is highly intriguing, and distinct from the presence of ANA and anti-histone antibodies during hydralazine treatment. At least three types of autoantibodies appear to have been induced by CMV, including anti-DNA and anticardiolipin antibodies, both of which are rare in drug-induced lupus. ${ }^{11}$ This observation supports the concept of virus-mediated autoimmunity. Several mechanisms may be involved, ${ }^{2}$ especially direct $\mathrm{B}$ cell activation by CMV.$^{12} \mathrm{CMV}$ infection was previously noted to be associated with the induction of several types of autoantibody and the rare appearance of autoimmune disease. ${ }^{2.13,14}$ Anticardiolipin and anti-DNA antibodies have both bee reported in viral infections, but levels were generally low and predominantly of IgM class, ${ }^{15}$ also suggesting antigen-independent mechanisms. ${ }^{16,17}$ Our patient's autoantibody titres were high but the pathogenetic significance of this response in acute infections, if there is any, is not known.

Thus, our report demonstrates a unique interaction of two environmental factors (hydralazine and acute CMV infection) in a female patient with a multifactorial genetic susceptibility (slow acetylator phenotype, HLA-DR4 and selective IgA deficiency), leading to a lupus-like autoimmune 
disease, which was nevertheless entirely and spontaneously reversible, demonstrating the important

\section{References}

1. Shoenfeld, Y. \& Schwartz, R.S. Immunologic and genetic factors in autoimmune diseases. $N$ Engl $J$ Med 1984, 311: 1019-1029.

2. Schattner, A. \& Rager-Zisman, B. Virus-induced autoimmunity. Rev Infect Dis 1990, 12: 204-222.

3. Schoen, R.T. \& Trentham, D.E. Drug-induced lupus: an adjuvant disease? Am J Med 1981, 71: 5-8.

4. Mansilla-Tinoco, R., Harland, S.J., Ryan, P.J. et al. Hydralazine antinuclear antibodies, and the lupus syndrome. $\mathrm{Br}$ Med J 1982, 284: 936-939.

5. Cameron, H.A.\& Ramsay, L.E. The lupus syndrome induced by hydralazine: a common complication with low dose treatment. Br Med J 1984, 289: 410-412.

6. Batchelor, J.R., Welsh, K.I., Mansilla-Tinoco, R. et al. Hydralazine-induced systemic lupus erythematosus: influence of HLA-DR and sex on susceptibility. Lancet 1980, 1: 1107-1110.

7. Horowitz, S. \& Hong, R. Selective IgA deficiency - some perspectives. In: Bergsma, D. (ed.) Birth Defects: Original Article Series XI. Sinauer, Sunderland, MA, 1975, pp. 129133.

8. Ammann, A.J. \& Fudenberg, H.H. Immunodeficiency diseases. In: Stites, D.P., Stobo, J.D., Fudenburg, H.H. \& Wells, J.V. (eds) Basic and Clinical Immunology, 4th edn. Lange, Los Altos, 1982, pp. 395-429.

9. Hess, E. Drug-related lupus. $N$ Engl $J$ Med 1988, 318: 1460-1462. role of environmental factors in the pathogenesis of autoimmunity.

10. Bluestein, H.G., Zvaifler, N.J., Weisman, M.H. \& Shapiro, R.F. Lymphocyte alteration by procainamide: relation to drug induced lupus erythematosus syndrome. Lancet 1979, 2: 816-819.

11. Weinstein, A. Laboratory diagnosis of drug-induced lupus. In: Lahita, R.G. (ed.) Systemic Lupus Erythematosus. Wiley \& Sons, New York, 1987, pp. 881-886.

12. Yachie, A., Tosato, G., Straus, S.E. \& Blaese, R.M. Immunostimulation by cytomegalovirus (CMV): helper T cell-dependent activation of immunoglobulin production in vitro by lymphocytes from CMV-immune donors. J Immunol 1985, 135: 1395-1340.

13. Andersen, P. \& Andersen, H.K. Smooth muscle antibodies and other tissue antibodies in cytomegalovirus infection. Clin Exp Immunol 1975, 22: 22-29.

14. Hart, I.K. \& Kennedy, P.G.E. Guillain-Barré syndrome associated with cytomegalovirus infection. $Q J M e d 1988,67$ : 425-430.

15. Maclean, C., Flegg, P.G. \& Kilpatrick, D.C. Anti-cardiolipin antibodies and HIV infection. Clin Exp Immunol 1990, 81: 263-266.

16. Steinberg, A.D. Immunology: aetiology of autoimmunity. Nature 1983, 304: 20.

17. Schattner, A. The origin of autoantibodies. Immunol Lett 1987, 14: 143-153. 